\title{
Pyro-Ecophysiology: Shifting the Paradigm of Live Wildland Fuel Research
}

\author{
W. Matt Jolly ${ }^{1, *(D)}$ and Daniel M. Johnson ${ }^{2}$ \\ 1 US Forest Service, Rocky Mountain Research Station, Fire Sciences Laboratory, 5775 Hwy 10 W, Missoula, \\ MT 59808, USA \\ 2 Department of Forest, Rangeland and Fire Sciences, University of Idaho, 875 Perimeter Drive MS 1133, \\ Moscow, ID 83844-1133, USA; danjohnson@uidaho.edu \\ * Correspondence: mjolly@fs.fed.us; Tel.: +1-406-329-4848
}

Received: 6 February 2018; Accepted: 12 February 2018; Published: 16 February 2018

\begin{abstract}
The most destructive wildland fires occur in mixtures of living and dead vegetation, yet very little attention has been given to the fundamental differences between factors that control their flammability. Historically, moisture content has been used to evaluate the relative flammability of live and dead fuels without considering major, unreported differences in the factors that control their variations across seasons and years. Physiological changes at both the leaf and whole plant level have the potential to explain ignition and fire behavior phenomena in live fuels that have been poorly explained for decades. Here, we explore how these physiological changes violate long-held assumptions about live fuel dynamics and we present a conceptual model that describes how plant carbon and water cycles independently and interactively influence plant flammability characteristics at both the leaf and whole plant scale. This new ecophysiology-based approach can help us expand our understanding of potential plant responses to environmental change and how those physiological changes may impact plant flammability. Furthermore, it may ultimately help us better manage wildland fires in an uncertain future.
\end{abstract}

Keywords: live fuels; fuel moisture; ecophysiology

\section{Introduction}

Wildland fires most commonly burn through mixtures of living and dead plants. Despite their importance, live fuels have received relatively little research interest because they are highly variable across space and time and they are typically difficult to standardize in either laboratory or field-based experiments. Early fuel flammability work relied heavily on fuel moisture content as a key predictor of seasonal and inter-annual fire potential [1]. This parameter was then incorporated into fire spread models in dead fuels [2], and later these models were expanded to include mixtures of living and dead fuels $[3,4]$. Live fuel moistures are generally an order of magnitude higher than dead fuel moistures, but during this early model development it was assumed that fuel moisture content alone could sufficiently describe the ignition and spread behavior differences between live and dead fuels; this assumption still persists in most live fuel flammability research [5-7]. Essentially, live fuels were simply assumed to be very wet dead fuels and nothing more. Further, significant emphasis is placed on the characteristics of individual fuel elements such as foliage, and flammability variations at the whole plant scale are also often ignored. This assumption implies that live fuels are simple, passive components of an ecosystem and it neglects centuries of ecophysiology research that demonstrate the dynamic nature of plants in response to environmental change. 


\subsection{Leaf-Level Linkages between Physiology and Flammability}

The fundamental flaw in our historical logic revolves around the assumption that fuel moisture content (FMC) is comparable between live and dead fuels. In its simplest form, fuel moisture content is the ratio of the weight of water in a fuel to the fuel's dry weight (Equation (1)):

$$
\text { Fuel Moisture Content }(\mathrm{FMC})=\text { Water Weight/Dry Weight }
$$

In dead fuels, dry weight is relatively constant and only changes slowly as a function of decomposition. Thus, dead fuel moistures track fuel water weight variations and are controlled by the direct diffusion and capillary transport of water into and out of the fuel [8,9]. The flawed assumption was made that live fuels behaved similarly and that only water weight varied over time. However, both the water weight and dry weight of live fuels changes diurnally $[10,11]$, seasonally $[12,13]$, and inter-annually [14]. Thus, FMC is derived from two metrics that vary independently over space and time. This confounds the interpretation of a single metric of plant flammability that is dominated by two competing processes. Interestingly, both of the quantities that are used to derive FMC are relevant to combustion. Water (FMC numerator) is important because it has a high specific heat and energy must be used to evaporate water before solid fuel can be raised to ignition temperature, thus increasing the energy required for ignition [15]. In contrast, when fuel dry matter (FMC denominator) is heated, it produces the pyrolyzates that support flaming combustion. Therefore both quantities of FMC can contribute to flammability and both vary independently over space and time. Further, leaf-scale characteristics can only go so far in explaining whole plant flammability, therefore it is also important to consider how foliage is arranged into the physical form of a plant. Thus, both leaf-level and plant-level characteristics should be considered in flammability studies.

A conceptual model for these linkages is shown in Figure 1. In live fuels, FMC varies through plant ecophysiological processes that are linked to both the water cycle (FMC numerator) and the carbon cycle (FMC denominator) (Figure 1). Water cycle processes such as soil water uptake, plant water storage, and water loss through transpiration all influence plant moisture status. Typical live fuel moisture modeling studies have focused on linking meteorological drought indicators with seasonal variations in FMC with moderate success [6,16]. It is likely that these drought metrics are proxies for plant water status, which is better measured using physiological water stress indicators such as water potential or relative water content [17]. Dry weight changes (FMC denominator) are most directly related to carbon cycle processes such as photosynthesis, respiration, carbon allocation, and canopy phenology, and dry weight changes alone have been shown to heavily influence live fuel ignitability [13]. Live FMC dynamics are most likely a combination of seasonal changes in actual water content and dry matter change $[12,18,19]$. Dry weight changes can be further decomposed into various chemical components, such as structural, non-structural, photosynthetic, and defensive compounds, and each of these sets of compounds can have a differing influence on leaf flammability [20]. Ultimately, decoupling the influences of water and dry matter dynamics and exploring their independent influences on combustion might be the best approach [12]. Ideally, it would be best for flammability studies to quantify both plant water stress with strong physiological indicators such as relative water content or leaf water potential as well as dry matter content variations in standard metrics such as leaf mass area that can capture within and between species variations in leaf mass (ovals, Figure 1). Then we can explore key ecophysiological drivers of these variations, such as plant water potentials and uptake from soils, photosynthetic and respiratory activity, carbon allocation, and phenology, to better understand how these characteristics change between species and over time in order to better understand connections between plant ecophysiology, climate, and wildland fire potential. Leaf-level physiological changes are important determinants of flammability, but how those leaves are aggregated into plants canopy can have an equal, or possibly even greater effect on their flammability. 


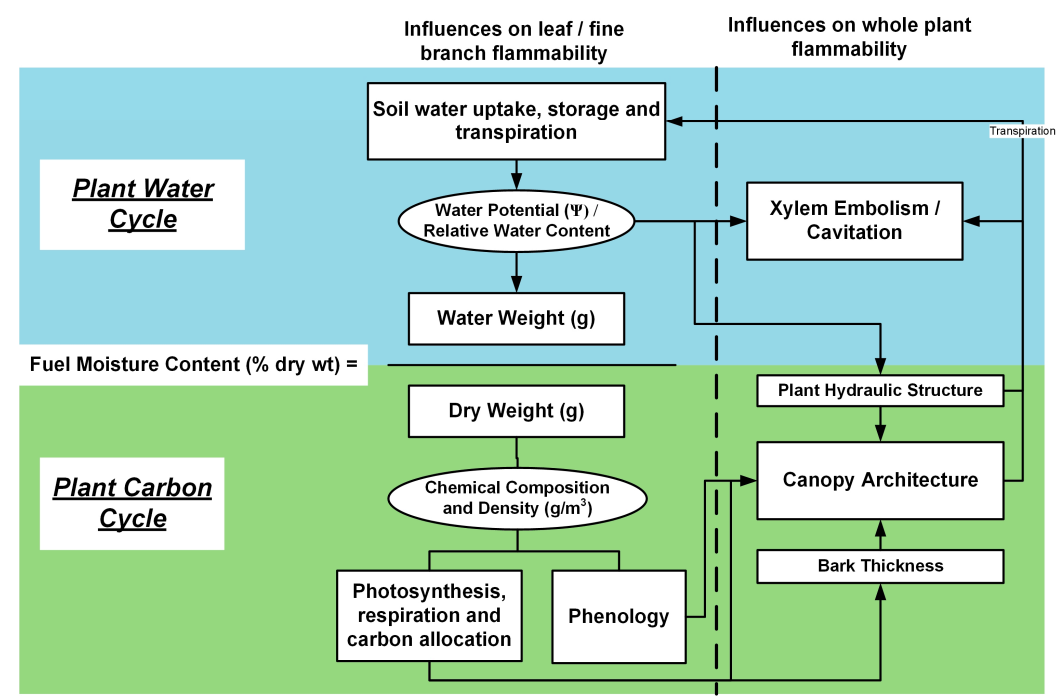

Figure 1. Conceptual model of the linkages between plant carbon and water cycles and how these two processes can individually impact fuel moisture content and subsequent leaf, branch, and whole plant flammability.

\subsection{Whole-Plant Level Linkages between Physiology and Flammability}

While many aspects of plant physiology can influence flammability at the leaf or small branch scale, other physiological constraints are more relevant at the whole plant level. Two important characteristics are canopy architecture and plant xylem embolism vulnerability (Figure 1).

Canopy architecture quantifies how a network of stems and foliage are arranged to efficiently collect and transform solar radiation through photosynthesis (carbon cycle) while minimizing water loss (water cycle). However, this arrangement of fuels can heavily impact the potential flammability of plants. Plant canopies must be sufficiently dense to ensure that fire can spread efficiently between foliage and canopies closer to the ground may be more easily ignited by a passing surface fire [21]. Foliar flame durations can be influenced by the arrangement of foliage in a canopy and the interactions between multiple particles [22]. Further, in canopies with mixtures of live and dead branches, canopy architecture can have a strong influence on fire temperatures and heat release [23]. Ultimately, plant canopy shapes are heavily evolved and distributions of different vegetation types are strongly influenced by climate [24]. Therefore, understanding how climate impacts canopy form and function can ultimately expand our knowledge of linkages between environment, canopy architecture, and subsequently plant flammability.

In addition to the external characteristics of plant architecture, plant hydraulics can influence tree scale flammability. First, examining the heating behavior of detached foliage in the absence of its connection to the plant may be a poor estimator of its burning behavior. Cohen and others [25] found that when branches were heated while still attached to the plant, they absorbed nearly $49 \%$ more energy than detached branches, which suggests that plant vascular systems can supply additional water to foliage when heated, as long as the plants are well hydrated. However, as plants become more water stressed, they are more susceptible to xylem embolism and cavitation [26], which breaks the flow of water from the roots to the leaves and could thus make plants behave like detached branches during heating. As fire passes under and through a plant canopy, very high vapor pressure deficits can be present on the surface of the foliage, and recent research suggests that this can increase xylem cavitation [27]. This effect may be particularly strong during periods of drought when plants have already experienced some degree of xylem embolism. Plant hydraulic vulnerability can also be influenced by other plant characteristics such as bark thickness. Bark thickness is species-dependent [28] and can directly influence fire-induced cambium necrosis [29] as well as influence stem xylem deformation and cavitation potential [30]. Ultimately, both the internal and 
external canopy characteristics can heavily impact whole plant burning behavior beyond the simple characteristics of individual foliage, and many of these processes can be more thoroughly explored by linking them to well-established ecophysiological processes.

\section{Summary: On the Need for a New Fire Science Discipline: Pyro-Ecophysiology}

The discipline of ecophysiology is defined as "... the study of how the environment, both physical and biological, interacts with the physiology of an organism" [31]. The primary interest of plant flammability research is to link observed changes in plant combustion characteristics to larger environmental changes such as climatic variations and intra-species variations. Historical work in live fuels has been essentially unfounded in core plant process principles that dictate and limit plant functioning, but rather those studies have focused primarily on correlations without the express intent of evaluating causality. The discipline of ecophysiology is rich and mostly unleveraged in live fuel research, yet it has the potential to link plant flammability traits at both the leaf and plant level to fundamental laws that govern how plants function. Consideration of plant ecophysiology within the context of live fuel flammability work has the potential to vastly expand our understanding of inter- and intra-species variations in flammability and how those characteristics may change over space and time. A new, ecophysiology-based approach to live fuel research that considers how plant water and carbon cycles independently and collectively interact at the leaf and whole plant level to regulate flammability and subsequent fire behavior could vastly improve our ability to predict intraand inter-species fire potential across both space and time. This discipline of pyro-ecophysiology is in its infancy, but the mechanisms of fire-induced changes in plant physiology, flammability, and the resulting mortality are already being explored [32-34]. This new approach can also help us expand our understanding of plants' potential responses to environmental change as well as how those physiological changes may impact plant flammability; moreover, it may ultimately help us better manage for fire under an uncertain future.

Author Contributions: W.M.J. and D.M.J. collaborated on the Perspectives context and co-wrote the paper.

Conflicts of Interest: The authors declare no conflict of interest.

\section{References}

1. Gisborne, H.T. Measuring Forest-Fire Danger in Northern Idaho; US Dept. of Agriculture: Washington, DC, USA, 1928.

2. Fons, W.L. Analysis of fire spread in light forest fuels. J. Agric. Res. 1946, 72, 93-121.

3. Anderson, H.E.; Rothermel, R.C. Influence of moisture and wind upon the characteristics of free-burning fires. Symp. (Int.) Combust. 1965, 10, 1009-1019. [CrossRef]

4. Rothermel, R.C. A Mathematical Model for Predicting Fire Spread in Wildland Fuels; USDA Forests Service Research Paper; Intermountain Forest and Range Experiment Station: Ogden, UT, USA, 1972.

5. Dimitrakopoulos, A.P.; Bemmerzouk, A.M. Predicting live herbaceous moisture content from a seasonal drought index. Int. J. Biometeorol. 2003, 47, 73-79. [PubMed]

6. Viegas, D.X.; Piñol, J.; Ogaya, R. Estimating live fine fuels moisture content using meteorologically-based indices. Int. J. Wildland Fire 2001, 10, 223-240. [CrossRef]

7. Xanthopoulos, G.; Wakimoto, R.H. A time to ignition - temperature - moisture relationship for branches of three western conifers. Can. J. For. Res. 1993, 23, 253-258. [CrossRef]

8. Nelson, R.M. Prediction of diurnal change in 10-h fuel stick moisture content. Can. J. For. Res. 2000, 30, 1071-1087. [CrossRef]

9. Viney, N.R. A review of fine fuel moisture modelling. Int. J. Wildland Fire 1991, 1, 215-234. [CrossRef]

10. Bertin, N.; Tchamitchian, M.; Baldet, P.; Devaux, C.; Brunel, B.; Gary, C. Contribution of carbohydrate pools to the variations in leaf mass per area within a tomato plant. New Phytol. 1999, 143, 53-61. [CrossRef]

11. Woodruff, D.R.; Meinzer, F.C.; Marias, D.E.; Sevanto, S.; Jenkins, M.W.; McDowell, N.G. Linking nonstructural carbohydrate dynamics to gas exchange and leaf hydraulic behavior in pinus edulis and juniperus monosperma. New Phytol. 2015, 206, 411-421. [CrossRef] [PubMed] 
12. Jolly, W.M.; Hadlow, A.M.; Huguet, K. De-coupling seasonal changes in water content and dry matter to predict live conifer foliar moisture content. Int. J. Wildland Fire 2014, 23, 480-489. [CrossRef]

13. Jolly, W.M.; Hintz, J.; Linn, R.L.; Kropp, R.C.; Conrad, E.T.; Parsons, R.A.; Winterkamp, J. Seasonal variations in red pine (pinus resinosa) and jack pine (pinus banksiana) foliar physio-chemistry and their potential influence on stand-scale wildland fire behavior. For. Ecol. Manag. 2016, 373, 167-178. [CrossRef]

14. Wever, L.A.; Flanagan, L.B.; Carlson, P.J. Seasonal and interannual variation in evapotranspiration, energy balance and surface conductance in a northern temperate grassland. Agric. For. Meteorol. 2002, 112, 31-49. [CrossRef]

15. Simms, D.; Law, M. The ignition of wet and dry wood by radiation. Combust. Flame 1967, 11, 377-388. [CrossRef]

16. Pellizzaro, G.; Cesaraccio, C.; Duce, P.; Ventura, A.; Zara, P. Relationships between seasonal patterns of live fuel moisture and meteorological drought indices for mediterranean shrubland species. Int. J. Wildland Fire 2007, 16, 232-241. [CrossRef]

17. Barrs, H.D.; Weatherley, P.E. A re-examination of the relative turgidity technique for estimating water deficits in leaves. Aust. J. Biol. Sci. 1962, 15, 413-428. [CrossRef]

18. Gary, H.L. Seasonal and diurnal changes in moisture contents and water deficits of engelmann spruce needles. Bot. Gaz. 1971, 327-332. [CrossRef]

19. Kozlowski, T.T.; Clausen, J.J. Changes in moisture contents and dry weights of buds and leaves of forest trees. Bot. Gaz. 1965, 126, 20-26. [CrossRef]

20. Finney, M.A.; Cohen, J.D.; McAllister, S.S.; Jolly, W.M. On the need for a theory of wildland fire spread. Int. J. Wildland Fire 2013, 22, 25-36. [CrossRef]

21. Van Wagner, C.E. Conditions for the start and spread of crown fire. Can. J. For. Res. 1977, 7, 23-34. [CrossRef]

22. Pickett, B.M.; Isackson, C.; Wunder, R.; Fletcher, T.H.; Butler, B.W.; Weise, D.R. Flame interactions and burning characteristics of two live leaf samples1. Int. J. Wildland Fire 2009, 18, 865-874. [CrossRef]

23. Schwilk, D.W. Flammability is a niche construction trait: Canopy architecture affects fire intensity. Am. Nat. 2003, 162, 725-733.

24. Whittaker, R.H. Communities and Ecosystems; Macmillan: New York, NY, USA, 1970.

25. Cohen, W.B.; Omi, P.N.; Kaufmann, M.R. Heating-related water transport to intact lodgepole pine branches. For. Sci. 1990, 36, 246-254.

26. Tyree, M.T.; Sperry, J.S. Vulnerability of xylem to cavitation and embolism. Ann. Rev. Plant Biol. 1989, 40, 19-36. [CrossRef]

27. Kavanaugh, K.L.; Dickinson, M.B.; Bova, A.S. A way forward for fire-caused tree mortality prediction: Modeling a physiological consequence of fire. Fire Ecol. 2010, 6, 80-94. [CrossRef]

28. Pausas, J.G. Bark thickness and fire regime. Funct. Ecol. 2015, 29, 315-327. [CrossRef]

29. Vines, R.G. Heat transfer through bark and the resistance of trees to fire. Aust. J. Bot. 1968, 16, 499-514. [CrossRef]

30. Michaletz, S.T.; Johnson, E.A.; Tyree, M.T. Moving beyond the cambium necrosis hypothesis of post-fire tree mortality: Cavitation and deformation of xylem in forest fires. New Phytol. 2012, 194, 254-263. [CrossRef] [PubMed]

31. Nature. Available online: https://www.nature.com/subjects/ecophysiology (accessed on 31 January 2018).

32. Smith, A.M.; Talhelm, A.F.; Johnson, D.M.; Sparks, A.M.; Kolden, C.A.; Yedinak, K.M.; Apostol, K.G.; Tinkham, W.T.; Abatzoglou, J.T.; Lutz, J.A. Effects of fire radiative energy density dose on pinus contorta and larix occidentalis seedling physiology and mortality. Int. J. Wildland Fire 2017, 26, 82-94. [CrossRef]

33. Sparks, A.M.; Kolden, C.A.; Smith, A.; Boschetti, L.; Johnson, D.; Cochrane, M.A. Fire intensity impacts on post-fire response of temperature coniferous forest net primary productivity. Biogeosciences 2018, in press.

34. West, A.G.; Nel, J.A.; Bond, W.J.; Midgley, J.J. Experimental evidence for heat plume-induced cavitation and xylem deformation as a mechanism of rapid post-fire tree mortality. New Phytol. 2016, 211, 828-838. [CrossRef] [PubMed]

(C) 2018 by the authors. Licensee MDPI, Basel, Switzerland. This article is an open access article distributed under the terms and conditions of the Creative Commons Attribution (CC BY) license (http:/ / creativecommons.org/licenses/by/4.0/). 